\title{
Management of post-traumatic craniovertebral junction dislocation: A PRISMA-compliant systematic review and meta-analysis of case reports
}

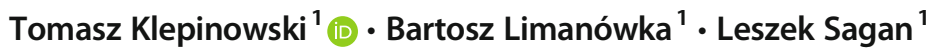 \\ Received: 1 May 2020 / Revised: 14 July 2020 / Accepted: 3 August 2020 / Published online: 14 August 2020 \\ (C) The Author(s) 2020
}

\begin{abstract}
Although historically considered fatal, with the advent of improved pre-hospital care, traumatic dislocation of the craniovertebral junction (CVJ) has been increasing in prevalence in neurosurgical centers. As more survivors are reported each year, a timely review with meta-analysis of their management seems necessary. PRISMA checklist was followed step by step. PubMed and Web of Science databases were searched using words "craniovertebral junction dislocation" and their corresponding synonyms. Study eligibility criteria included research studies from 2015 onwards that delineated adult and pediatric patients with confirmed post-traumatic atlantooccipital dislocation (AOD) or atlantoaxial dislocation (AAD) who survived until proper treatment. Of 1475 initial records, 46 articles met eligibility criteria with a total of 141 patients with traumatic CVJ dislocation. Of the patients, 90 were male (63.8\%). Mean age of the cohort was 33.3 years (range 1-99 years). Trauma that most often led to this injury was road traffic accident $(70.9 \%)$ followed by falls $(24.6 \%)$. The majority of authors support posterior instrumentation of C1-C2 (45.2\%) especially by means of Goel-Harms method. At mean follow-up of 15.4 months (range $0.5-60$ months), $27.2 \%$ of treated patients remained neurologically intact. Of initially symptomatic, 59\% improved, 37\% were stable, and $4 \%$ deteriorated. Instrumenting the occiput in cases of pure $\mathrm{AAD}$ was associated with lower chance of neurological improvement in chi-square test $(p=0.0013)$ as well as in multiple linear regression $(\beta=-0.3 ; p=0.023)$. The Goel-Harms C1-C2 fusion is currently the most frequently employed treatment. Many survivors remain with no deficits or improve, rarely deteriorate. Involving the occiput in stabilization in cases of AAD without AOD might be related with worse neurological prognosis.
\end{abstract}

Keywords Craniovertebral junction dislocation $\cdot$ Trauma $\cdot$ Atlantoaxial joint $\cdot$ Atlantooccipital joint

\section{Introduction}

Craniovertebral junction (CVJ) is a term encompassing occipitoatlantal and atlantoaxial complex of joints and ligaments. The former of the joints is said to provide stability, whereas the latter is responsible for the wide range of motion, accounting for more than half of the cervical spine rotation [1-3]. Dislocation of the junction happens when the integrity

Electronic supplementary material The online version of this article (https://doi.org/10.1007/s10143-020-01366-4) contains supplementary material, which is available to authorized users.

Tomasz Klepinowski

tomasz.klepinowski@pum.edu.pl

1 Department of Neurosurgery, Pomeranian Medical University Hospital No. 1, Szczecin, Poland of the articular capsule is breached and might occur at each of the joints. Furthermore, it may be of congenital, inflammatory, or traumatic etiology. Traumatic dislocation of craniovertebral junction, although once considered fatal, has been proven numerous times that it can be a survivable injury [4]. It is mainly due to improvement made in the pre-hospital stage of care. Therefore, more and more survivors are encountered who require proper stabilization, which can be either conservative or surgical. Traumatic atlantooccipital dislocation (AOD) constitutes $1 \%$ of all injuries to the cervical spine and is believed to be less common than traumatic atlantoaxial dislocation (AAD) which constitutes $2.7 \%$ [5].

Rationalizing the study, we found no systematic review on the post-traumatic $\mathrm{CVJ}$ dislocation. Hence, considering recent advances in resuscitation, radiological diagnostic tools, and increasing choice of neurosurgical options, a timely review seems necessary. Utilizing the structured guidelines of the 
PRISMA (Preferred Reporting Items for Systematic Reviews and Meta-Analyses) group has become a standard for highquality review studies. As proven by Sampayo-Cordero et al. in 2018 [6], a meta-analysis of case reports is accurate and agrees with a meta-analysis of clinical randomized studies and is dedicated for rare diseases that often times have zero events in either both arms. Since adequate records of post-traumatic CVJ are reported solely in case reports or case series, a metaanalysis based on case reports is well rationalized. This study aims to answer questions of what state-of-the-art treatment patients with traumatic dislocation of $\mathrm{CVJ}$ are currently receiving, what outcomes they are likely to obtain, and whether plating the occiput affects patients' outcome.

\section{Materials and methods}

PRISMA checklist was followed step by step (Electronic Supplementary Material No. 1). Participants, interventions, context, outcome, and study designs are shown in Table 1. On 17 February 2020, two databases, PubMed Medline and Web of Science, were perused using search words "craniovertebral junction dislocation" and their corresponding synonyms. Full electronic search strategy can be found here (Electronic Supplementary Material No. 2).

Eligibility criteria included latest research studies from 2015 to 2020 that delineated patients with post-traumatic craniovertebral junction dislocation. We defined dislocation as a ligamentous injury with ensuing misalignment of the facets. Thus, what was searched was radiological evidence of either obvious loss of facetal contact or positive testing for classic radiological markers. Concomitant lesions or fractures within the CVJ were acceptable as long as post-traumatic facetal misalignment was present. Inclusion and exclusion criteria are shown in Table 2. Extraction of the data from the gathered reports was conducted by the first author (TK) and then independently checked and confirmed by the co-authors (BL and LS) so as to ensure minimal risk of bias of individual studies. Collected variables included number of traumatic cases in a given publication, patients' sex, age, mechanism of trauma, resultant injury, underlying disease (if present), therapeutic interventions, levels of fusion, surgical technique, and outcomes (subjective pain analysis, neurological assessment, fusion rates) at a specified follow-up period. Conservative treatment information was retrieved only when there was no subsequent surgery. If a patient received both conservative and surgical management, focus was on the latter. Pain relief as an outcome was noted only if there was pain at presentation. Thus, a documented change in pain intensity after treatment was searched for extraction. Neurological status was assessed both preoperatively and postoperatively and tendency was written down. Accepted forms of neurological status assessment were as follows: quantified scores of myelopathic grading systems such as Japanese Orthopedic Association (JOA) score, its modified variant (mJOA), American Spinal Injury Association (ASIA) score, Nurick score, as well as authors' subjective examination. Due to lack of unified neurological assessment methods among the authors, gross tendencies were grouped into the following categories: remained intact, improved, stable, and deteriorated. Additionally, fusion rates were collectedfusion was defined as documented lack of movement of the stabilized joints assessed on lateral X-ray. Subjective authors' statement of solid fusion was acceptable. Although subjectivity adds a risk of bias, we assumed that proper radiological assessment had been done in order to declare fusion. No funding was expected at the beginning of the study and none was obtained throughout the process. Statistical analysis of the data was performed by means of Statistica 13 (TIBCO Software Inc.). Pearson's chi-square test would be used for categorical variables, whereas continuous variables would be computed by WilcoxonMann-Whitney or Kruskal-Wallis test. Multiple linear regression was used to assess relations between neurological change at follow-up (dependent variable) and sex, age, type of dislocation, and plating the occiput (independent variables).

\section{Results}

The PRISMA flow diagram shows steps of the inclusion process (Fig. 1). Initial search presented 1475 titles. Having

Table 1 PICOS acronym describing characteristics of this review study

\begin{tabular}{lll}
\hline Acronym & Definition & This study \\
\hline $\mathrm{P}$ & Participants & Children and adults with post-traumatic AOD, AAD, or both who survived until treatment \\
$\mathrm{I}$ & Intervention & $\begin{array}{r}\text { Anterior or posterior reduction and instrumentation with levels of fusion and status of occipital } \\
\text { involvement. If there was no surgery, conservative management details of traction and bracing would be presented }\end{array}$ \\
& & Trauma-its mechanism as well as basic demographic data of patients \\
$\mathrm{C}$ & Context & Neck pain, NDI, JOA, mJOA, Nurick scale, ASIA, subjective improvement, fusion rates \\
$\mathrm{O}$ & Outcome & Cross-sectional and longitudinal cohort studies, case series $(n \geq 3)$, case reports $(n \leq 2)$ \\
$\mathrm{S}$ & Study designs
\end{tabular}

AAD, atlantoaxial dislocation; AOD, atlantooccipital dislocation; ASIA, American Spinal Injury Association Impairment Scale; mJOA, modified Japanese Orthopedic Association score; NDI, neck disability index 
Table 2 Inclusion and exclusion criteria for the studies screened and checked for eligibility

Inclusion criteria
1. Publications from 2015 to 2020
2. Dislocation of atlantooccipital or atlantoaxial joints
3. Trauma as the primary cause (underlying diseases
and fractures are acceptable)
4. Adequate records for evaluation
5. Full text available in English or Polish
6. Treatment method listed

Exclusion criteria

1. Reoperations

2. Commentaries

3. Review articles

4. Radiological articles

5. Insufficient medical history

6. Cadaveric or animal studies

7. Subject died before treatment was employed

8. Dislocation due to non-traumatic causes (congenital, inflammatory, syndromic) removed duplicates, 894 titles and abstracts were collected for screening (Table 3). A total of 46 full-text articles were deemed eligible for inclusion [3, 7-50]. The highest level of evidence of the included papers was IV. They comprised 141 cases, 90 of which were male $(63.8 \%), 46$ were female $(32.6 \%)$, and gender of 5 patients was not stated. Mean age of the cohort was 39.2 years (range 8 months to 99 years). For adults mean age was 46.7 years (range 19-99 years). On the other hand, in the pediatric subpopulation, mean age was 4.9 years (range 8 months to 17 years). Mechanism of injury was known in 110 patients $(78.0 \%)$. Among them, the most common trauma was road traffic accident $(n=78)$ accounting for more than two-thirds of the cases $(70.9 \%)$. Falls were the second leading cause of the traumatic CVJ dislocation constituting nearly a quarter of cases $(24.6 \%)$. Occasionally, jumping headfirst into the water, assault, epileptic seizure, or being hit by a falling object might also lead to this condition (altogether $4.5 \%$ ). Diagnosis in majority of cases was atlantoaxial dislocation $(62.4 \%, n=88)$, followed by atlantooccipital dislocation $(27.7 \%, n=39)$ and combined AAD with AOD $(9.9 \%, n=14)$. Most authors go for surgical management even if initial nonoperative reduction was achieved. In total, $95.7 \%(n=135)$ were operated on at some point, either as a primary treatment option or as a result of
Fig. 1 A flow diagram depicting the process of including studies into the review and meta-analysis
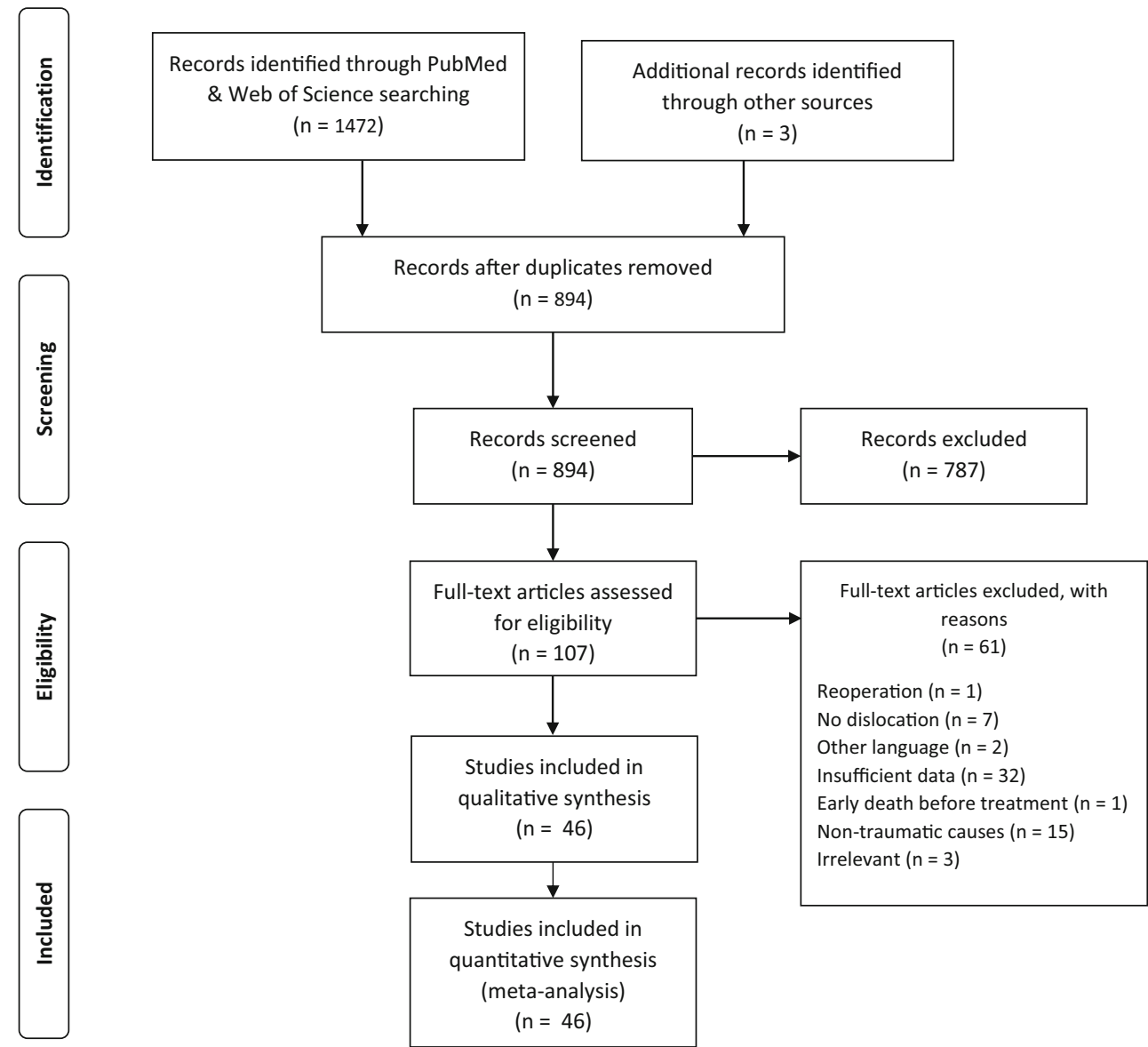


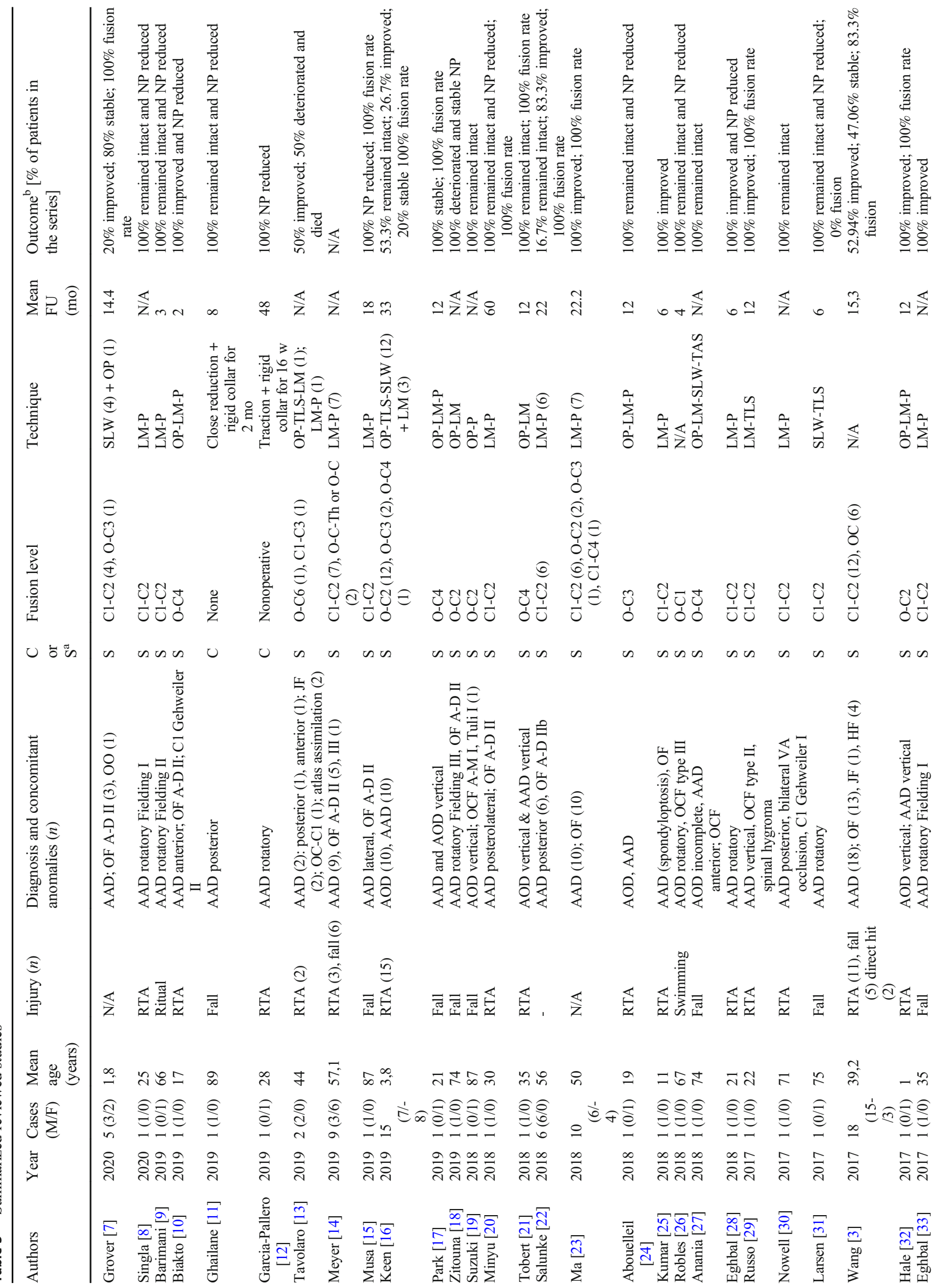




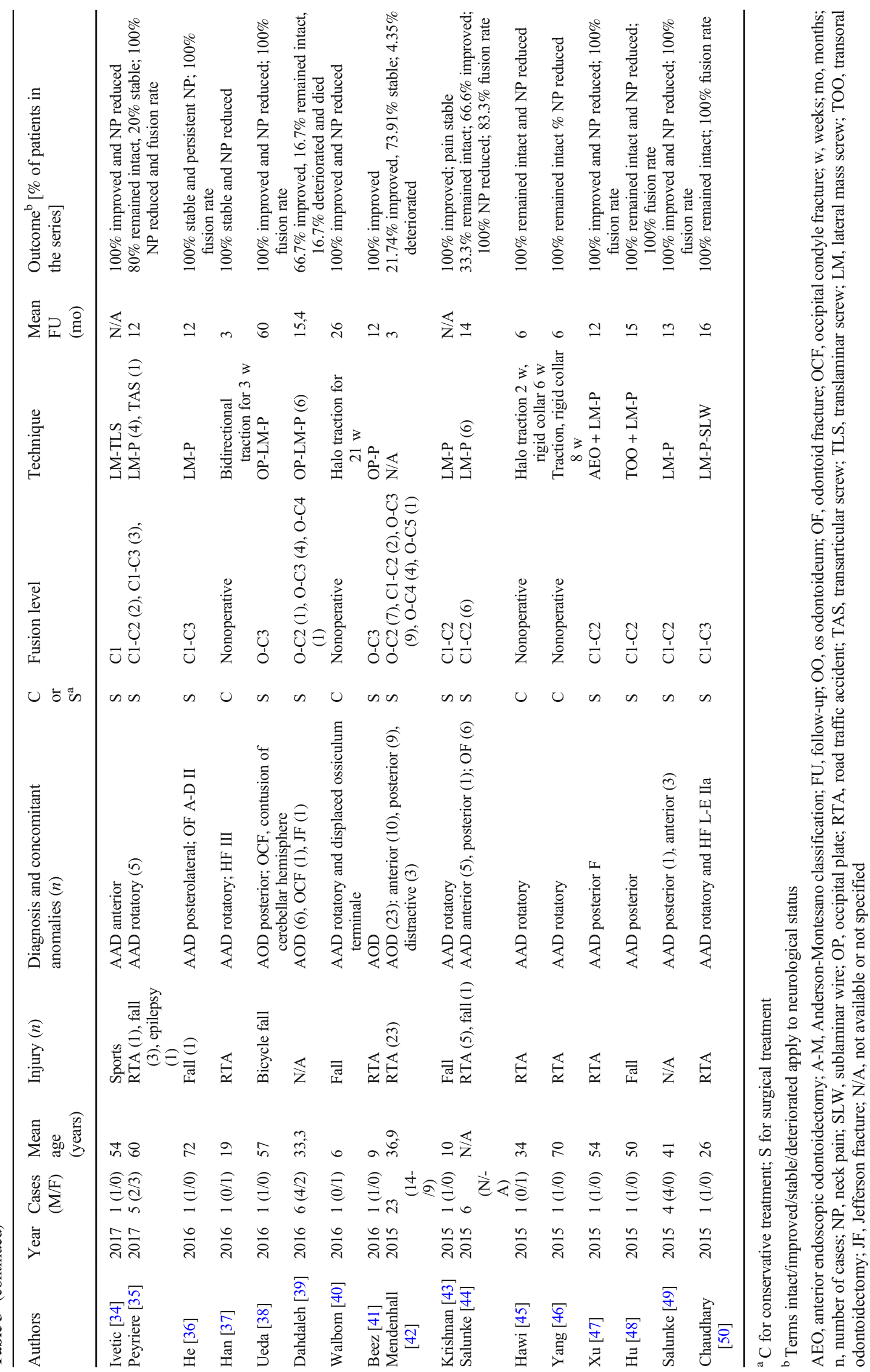


failed initial conservative management. Levels that were subject of fusion most frequently were as follows: C1-C2 (45.2\%, $n=61), \mathrm{O}-\mathrm{C} 2(19.3 \%, n=26), \mathrm{O}-\mathrm{C} 3(13.3 \%, n=18), \mathrm{O}-\mathrm{C} 4$ $(8.1 \%, n=11)$, and $\mathrm{C} 1-\mathrm{C} 3(4.4 \%, n=6) .8 .1 \%$ of the treated $(n=11)$ were either unspecified or other levels (Fig. 2). For AOD the most common level of stabilization was O-C2 (35.9\%, $n=14)$. Similarly for combined AOD with AAD, O-C2 was usually fused $(57.1 \%, n=8)$. Choice of level differed significantly for AAD and AOD $(p<0.001) .4 .3 \%(n=$ 6 ) of all patients were treated conservatively with no subsequent surgery. All those nonoperative cases regarded atlantoaxial dislocation, but none atlantooccipital dislocation. This, however, was not statistically significant ( $p=0.129$, chisquare test). Neurological status prior to treatment was known in $97.2 \%(n=137)$ of patients. Its quantification by means of JOA, mJOA, Nurick scale, or ASIA was done in 70 cases $(49.6 \%)$. The remaining was authors' subjective examination. $27.2 \%(n=37)$ were neurologically intact and remained so at follow-up, whereas $76.3 \%(n=100)$ had neurological deficits on initial examination. Among the latter, 59\% improved $(n=$ $59), 37 \%$ were stable $(n=37)$, and $4 \%$ deteriorated $(n=4)$. Of all, 49.6\% $(n=70)$ had their occipital bone involved in instrumentation. Within the group with initial neurological signs, patients without the occiput instrumentation were more likely to improve (48.1\% vs $33.3 \%$ ) and less likely to remain neurologically stable $(9.3 \%$ vs $41.7 \%)$ ( $p=0.0013$, chi-square test; regards mainly pure AAD patients) at a mean follow-up of 15.4 months (range $0.5-60$ months). Hindered improvement after plating the occiput was observed also in multiple linear regression model with the following dependent variables: mean age, sex, type of dislocation, and plating the occiput (Table 4). Debilitating neck pain was reported preoperatively by 43 patients $(30.5 \%)$. Of those, at follow-up visit, neck pain improved in 36 patients $(83.7 \%)$. Change in pain at a follow-up was not correlated with the status of occipital plating ( $p=0.4091)$. Assessment of fusion rate was done in 81 survivors (57.4\%). At follow-up visits, solid fusion was declared in $76(93.8 \%)$.

\section{Discussion}

In this study, we touched upon several important aspects. As Winegar et al. in 2010 noted, neck pain improvement after treatment of dislocation of CVJ is generally highest in traumatic cohort [51]. They had detailed information on pain in 28 post-traumatic cases, and improvement after treatment was seen in $22(78.57 \%)$. Our review gathered data on pain from 43 patients with improvement of $83.7 \%(n=36)$, confirming a high rate of pain alleviation in this group. According to the literature, after cervical injury, over $60 \%$ of survivors experience pain within the first $6 \mathrm{~h}$, over $90 \%$ after a day, and basically everyone after 3 days following the trauma [52]. Fortunately, as we presented, successful stabilization paired with further rehabilitation can mitigate it better than in cases of other CVJ abnormalities. Importantly, as Debernardi noticed, if neck pain and stiffness are mild to moderate, it is more likely to overlook the diagnosis [53].

Atlantooccipital joint is regarded as the most stable joint of the body, whereas atlantoaxial joint as the most mobile one [1, 54]. Mobility of the latter, however, is the source of its susceptibility to dislocation. Hence, most cases of the CVJ dislocation happen at the atlantoaxial level. Atul Goel is convinced that majority of AAD do not require involvement of the occiput because there is no concurrent AOD [55]. He states that primary AAD needs only segmental fixation. Extensive multiple-level stabilization compromises the strength of the fusion. In addition, immobilization of both crucial units considerably reduces range of motion. Nevertheless, we showed that $18.2 \%$ of patients with pure AAD $(n=16)$ had occipitocervical stabilization. This might be even of higher importance considering the fact that in the presented analysis, involvement of the occipital bone was associated with lower chance of neurological improvement and higher risk of neurological stagnation, especially in cases of pure AAD without AOD. These findings, however, require confirmation in larger prospective studies. Authors of this review generally accept Goel's attitude that occipitocervical fusion is appropriate and
Fig. 2 A graph showing levels of instrumentation that were addressed most frequently. A number of patients with fusion at a given level are shown above the bars

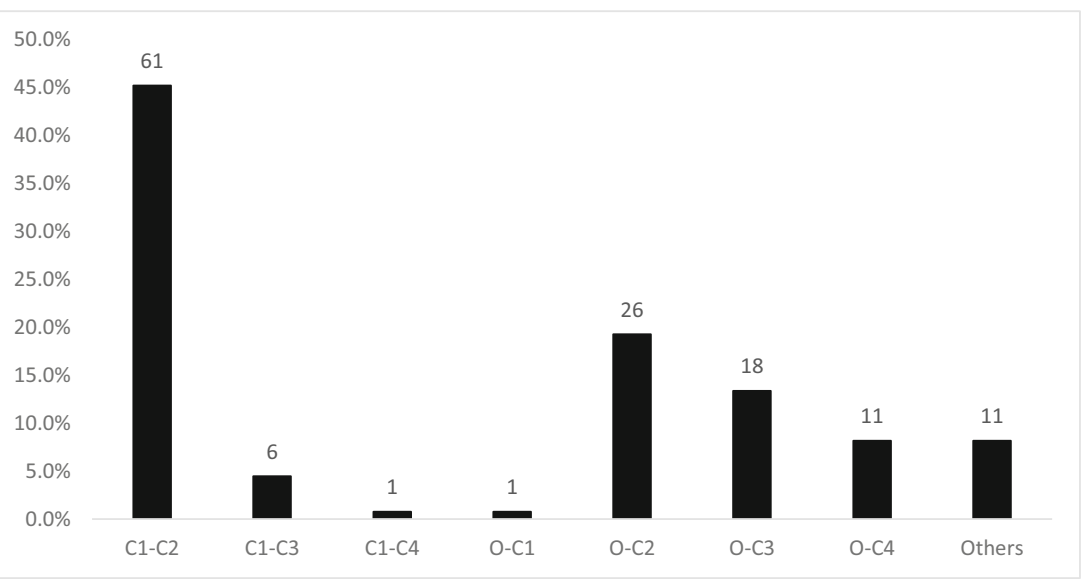


Table 4 Multiple linear regression model to determine factors associated with neurological status at follow-up visits in patients with craniovertebral junction dislocation

Neurological status at follow-up

\begin{tabular}{lcc}
\cline { 2 - 3 } Variable & \multicolumn{2}{c}{$p$} \\
\hline Age at operation & -0.08 & 0.514 \\
Sex (F/M) & 0.19 & 0.120 \\
Type of dislocation (AOD/AAD) & 0.12 & 0.307 \\
Plating the occiput (no/yes) & -0.30 & 0.023 \\
\hline
\end{tabular}

indicated in confirmed atlantooccipital dislocation. Good radiological markers for combined AAD and AOD facilitating decision-making seem to be basion-dental interval (BDI), revised $\mathrm{C} 1$-condyle interval ( $\mathrm{rCCI}$ ), and basion-axial interval (BAI) [56]. Especially rCCI with cut-off value of $2.5 \mathrm{~mm}$ has high sensitivity and specificity [56].

Our analysis revealed that a method of fusion which was chosen most often was Goel-Harms technique. C1-C2 segment was targeted in 61 patients. Of them, 49 had their construct details reported. Thirty-seven patients (75.5\%) had implanted screws/rod construct in accordance with Goel-Harms approach. Rarely did authors from the selected studies choose wiring, and if so, it was mostly in children. From historical perspective, wiring was among the first of techniques introduced to the CVJ battlefield. Although wiring has shortest time to fusion, its failure rate is higher than that of GoelHarms' rod-screw construct passing through the lateral masses of $\mathrm{C} 1$ and the pedicles of $\mathrm{C} 2$ [51].

In 1994, Goel introduced a concept of placing screws into both $\mathrm{C} 1$ lateral masses and $\mathrm{C} 2$ pedicles [57]. His initial idea back then was to put it monocortically. It was not until 2001 when Harms published his work stressing that bicortical purchase was desired [58]. Harms improved Goel's approach by applying polyaxial screws bicortically which provided stability for fully loaded rod connection. Goel-Harms C1-C2 fixation has several advantages over the classic Magerl's transarticular technique. First of all, it does not sacrifice the facets of the first two vertebrae. Omitting disruption of the capsule renders it potentially reversible which might save the range of motion after removal of the construct once the fracture has healed. Also, an angle required to perform the Goel-Harms stabilization is significantly easier to achieve since it is only $\sim 22$ degrees cephalad when compared with $\sim 50$ degrees of the Magerl [59-61]. Finally, the Goel-Harms procedure provides a way for one-stage open reduction of the dislocation and fusion utilizing the same anesthesia period and the same positioning [49,61].

In this paper, sixteen patients $(12.4 \%$ of the operatively treated) had translaminar screws implanted. This concept was introduced in 2004 by Wright [62]. One of the conditions that needs to be met is transverse diameter of the lamina larger than $3.5 \mathrm{~mm}$ [63]. Moreover, C1 lateral mass-C2 laminar method is inferior to Goel-Harms in terms of the stability during lateral bending and axial rotation [64]. It also poses a higher risk of damaging the spinal cord [65]. Additionally, from biomechanical point of view, it is not suitable for longer subaxial constructions when concomitant instabilities are present. However, it can be considered a rescue procedure in situations when $\mathrm{C} 2$ pedicle screws cannot be used.

Recently, new techniques began to emerge such as anterior transcervical or transnasal endoscopic odontoidectomy with reduction of the dislocation $[47,66,67]$. There was one such a case in our review. Notably, it is helpful in posterior atlantoaxial dislocation without associated dental fracture when the dens moves anteriorly and is challenging to reduce otherwise. Odontoidectomy might also be performed in a scarless fashion. These are, however, limited options for traumatic patients because of frequent concomitant nasofacial injuries as the most common mechanism of CVJ dislocation is still highspeed road traffic accident.

Our review sheds light upon the lack of unison in terms of methodology of reporting traumatic craniocervical junction sequelae. Too many potentially contributory papers had to be excluded because of insufficient data. Posttraumatic patients are often not distinguished from the reported cohort because of their relatively small number. It is understood that merging etiologies of the CVJ dislocation produces larger series, but it is at a cost of heterogeneity. One solution to this might be providing more details on the subgroups within the mixed series. Furthermore, for case reports as well as case series, it is recommended to furnish detailed and quantified neurological examination done prior to surgery and thereafter. Additional assessment at a distant follow-up would also be of high informative value. Obviously, for part of posttraumatic patients, preoperative evaluation is very challenging due to their poor general state. Those with delayed presentation, however, could be examined thoroughly with at least one of the following scales: mJOA, JOA, ASIA, or Nurick.

\section{Limitations}

First limitation of this research is absence of evidence stronger than level IV. Most authors report their cases in small series, rarely with any control group. Therefore, a meta-analysis based entirely on case reports/case series was carried out. This might bias the scientific truth because there is a tendency to present rather positive outcomes in case reports. Another restraint might be a scope of years of the included papers. We believe, however, that some relevant progress had been made 
in the field of resuscitation, diagnostic tools, and neurosurgical management of the craniovertebral junction dislocation; therefore, only new publications from the last half a decade were accepted. Finally, lack of unanimous agreement on the manner in which outcomes are reported renders the outcome variable categorical rather than continuous.

\section{Conclusion}

Traumatic dislocation of CVJ is no longer equivalent to death. Due to advances in pre-hospital care, it has become a survivable injury. In-hospital management of choice is timely reduction, at first close with monitoring the patient's status. In case of irreducible dislocation, open reduction is mandatory with subsequent stabilization. For atlantoaxial dislocation with no other abnormalities of the cervical vertebrae, posterior C1-C2 fusion with the Goel-Harms method is the most appreciated approach, currently regarded as the gold standard. For atlantooccipital dislocation, occipitocervical instrumentation yields satisfactory results. For combined AAD and AOD, superior extension for Goel-Harms technique towards the occiput by means of occipital plating is recommended. Many survivors remain with no deficits or improve, rarely deteriorate. Involving the occiput, especially for pure $\mathrm{AAD}$, might be related with hindered neurological improvement.

Acknowledgments The authors would like to acknowledge all the researchers that contributed to the studies included in this review.

Funding Information Open access funding provided by Pomeranian Medical University in Szczecin.

\section{Compliance with ethical standards}

Conflict of interest The authors declare that they have no conflict of interest.

Ethical approval For this type of study formal consent is not required.

Consent to participate As this was a retrospective analysis of the studies that had been published in the past, no consent to participate was necessary.

Consent for publication The authors of this study grant the Publisher the sole and exclusive license of the full copyright.

Open Access This article is licensed under a Creative Commons Attribution 4.0 International License, which permits use, sharing, adaptation, distribution and reproduction in any medium or format, as long as you give appropriate credit to the original author(s) and the source, provide a link to the Creative Commons licence, and indicate if changes were made. The images or other third party material in this article are included in the article's Creative Commons licence, unless indicated otherwise in a credit line to the material. If material is not included in the article's Creative Commons licence and your intended use is not permitted by statutory regulation or exceeds the permitted use, you will need to obtain permission directly from the copyright holder. To view a copy of this licence, visit http://creativecommons.org/licenses/by/4.0/.

\section{References}

1. Goel A (2015) Craniovertebral junction instability: a review of facts about facets. Asian Spine J 9:636-644. https://doi.org/10.4184/asj. 2015.9.4.636

2. Goel A (2016) Central or axial atlantoaxial instability: expanding understanding of craniovertebral junction. J Craniovertebr Junction Spine 7:1-3. https://doi.org/10.4103/0974-8237.176602

3. Wang L, Gu Y, Chen L, Yang H (2017) Surgery for chronic traumatic atlantoaxial dislocation associated with myelopathy. Clin Spine Surg 30:E640-E647. https://doi.org/10.1097/BSD. 0000000000000272

4. Cooper Z, Gross JA, Lacey JM, Traven N, Mirza SK, Arbabi S (2010) Identifying survivors with traumatic craniocervical dissociation: a retrospective study. J Surg Res 160:3-8. https://doi.org/10. 1016/j.jss.2009.04.004

5. Pissonnier ML, Lazennec JY, Renoux J, Rousseau MA (2013) Trauma of the upper cervical spine: focus on vertical atlantoaxial dislocation. Eur Spine J 22:2167-2175. https://doi.org/10.1007/ s00586-013-2841-2

6. Sampayo-Cordero M, Miguel-Huguet B, Pardo-Mateos A, MoltóAbad M, Muñoz-Delgado C, Pérez-López J (2018) Agreement between the results of meta-analyses from case reports and from clinical studies regarding the efficacy of laronidase therapy in patients with mucopolysaccharidosis type I who initiated enzyme replacement therapy in adult age: an example of case. Mol Genet Metab 123:69-75. https://doi.org/10.1016/j.ymgme.2018.01.002

7. Grover PJ, Harris LS, Thompson DNP (2020) Craniovertebral junction fixation in children less than 5 years. Eur Spine J. https:// doi.org/10.1007/s00586-020-06313-x

8. Singla R, Manjunath N, Sharma R, Mishra S (2020) Neglected traumatic atlantoaxial rotatory dislocation in adult: a case report. Int J Spine Surg 14:7006. https://doi.org/10.14444/7006

9. Barimani B, Fairag R, Abduljabbar F, Aoude A, Santaguida C, Ouellet J, Weber M (2019) A missed traumatic atlanto-axial rotatory subluxation in an adult patient: case report. Open Access Emerg Med 11:39-42. https://doi.org/10.2147/OAEM.S149296

10. Biakto KT, Arifin J, Lee J, Benjamin M (2019) Occipitocervical fusion and posterior fossa decompression in neglected jefferson fracture-dislocation of atlas associated with odontoid peg fracture: a case report. Int J Spine Surg 13:11-16. https://doi.org/10.14444/ 6001

11. Ghailane S, Alsofyani MA, Pointillart V, Bouloussa H, Gille O (2019) Traumatic posterior atlanto-axial dislocation: case report of an atypical C1-C2 dislocation with an anterior arch fracture of $\mathrm{C} 1$. BMC Musculoskelet Disord 20. https://doi.org/10.1186/s12891019-3005-2

12. García-Pallero MA, Torres CV, Delgado-Fernández J, Sola RG (2019) Traumatic atlantoaxial rotatory fixation in an adult patient. Eur Spine J 28:284-289. https://doi.org/10.1007/s00586-0164916-3

13. Tavolaro C, Pulido H, Bransford R, Bellabarba C (2019) Traumatic craniocervical dissociation in patients with congenital assimilation of the atlas to the occiput. Case Rep Orthop 2019:1-7. https://doi. org $/ 10.1155 / 2019 / 2617379$

14. Meyer C, Eysel P, Stein G (2019) Traumatic atlantoaxial and fracture-related dislocation. Biomed Res Int 2019. https://doi.org/ $10.1155 / 2019 / 5297950$ 
15. Musa A, Farhan SA, Lee YP, Uribe B, Kiester PD (2019) Traumatic atlantoaxial lateral subluxation with chronic type II odontoid fracture: a case report. Int J Spine Surg 13:79-83. https://doi.org/10.14444/6010

16. Keen JR, Ayer RE, Taha A, Zouros A (2019) Rigid internal fixation for traumatic cranio-cervical dissociation in infants and young children. Spine (Phila Pa 1976) 44:17-24. https://doi.org/10.1097/ BRS.0000000000002741

17. Park JB, Chang DG, Kim WJ, Kim ES (2019) Traumatic combined vertical atlanto-occipital and atlanto-axial dislocations with 2-part fracture of the atlas: two case reports. Medicine (Baltimore) 98: e17776. https://doi.org/10.1097/MD.0000000000017776

18. Zitouna K, Riahi H, Lassoued N, Selmene M, Barsaoui M, Drissi G (2019) Traumatic atlantoaxial dislocation with an odontoid fracture: a rare and potentially fatal injury. Asian J Neurosurg 14:1249. https://doi.org/10.4103/ajns.ajns_214_19

19. Suzuki T, Maki S, Aramomi M, Yamauchi T, Horii M, Kawamura K, Sugiyama H, Ohtori S (2018) Occipital condyle fracture: a case report of a typically stable fracture that required surgical treatment. Case Rep Orthop 2018:1-3. https://doi.org/10.1155/2018/2809546

20. Minyu Z, Shiyang W, Suraj C, Kelun H, Chaowei L, Honglin T (2018) Traumatic posterolateral C1-C2 dislocation complicated with locked lateral mass and type II odontoid fracture-5-year follow-up. World Neurosurg 114:330-334. https://doi.org/10.1016/j. wneu.2018.03.191

21. Tobert DG, Ferrone ML, Czuczman GJ (2018) Traumatic atlantooccipital dissociation and atlantoaxial instability: concomitant ligamentous injuries without neurologic deficit: a case report. JBJS Case Connect 8:e62. https://doi.org/10.2106/JBJS.CC.18.00021

22. Salunke P, Sahoo SK (2018) Irreducible Posterior C1-2 Dislocation with Retrolisthesis of Dens: Hindsight from 10 Cases. World Neurosurg 123:e202-e210. https://doi.org/10.1016/ j.wneu.2018.11.124

23. Ma F, Kang M, Liao Y h, Lee G z, Tang Q, Tang C, Wang Q, Zhong D j (2018) The use of intraoperative traction for achieving reduction of irreducible atlantoaxial dislocation caused by different craniovertebral junction pathologies. Clin Neurol Neurosurg 175: 98-105. https://doi.org/10.1016/j.clineuro.2018.10.016

24. Abouelleil M, Siddique D, Dahdaleh N (2018) Failure of the condyle-C1 interval method to diagnose atlanto-occipital dislocation in the presence of an associated atlanto-axial dislocation: a case report. Cureus. https://doi.org/10.7759/cureus.2486

25. Kumar A, Varshney G, Singh PK, Agrawal D, Satyarthee GD, Chandra PS, Kale SS, Mahapatra AK (2018) Traumatic atlantoaxial spondyloptosis associated with displaced odontoid fracture: complete reduction via posterior approach using "joint remodeling" technique. World Neurosurg 110:609-613. https://doi.org/10. 1016/j.wneu.2017.09.097

26. Robles LA, Mundis GM, Cuevas-Solórzano A (2018) Atlantooccipital rotatory dislocation: a case report and systematic review. World Neurosurg 110:106-114. https://doi.org/10.1016/j.wneu. 2017.11.005

27. Anania P, Fiaschi P, Sbaffi PF, Zona G (2018) A case of asymptomatic occipital condyle fracture with incomplete occipitocervical dislocation: how did it happen? World Neurosurg 109:403-408. https://doi.org/10.1016/j.wneu.2017.10.082

28. Eghbal K, Rakhsha A, Saffarrian A, Rahmanian A, Abdollahpour HR, Ghaffarpasand F (2018) Surgical management of adult traumatic atlantoaxial rotatory subluxation with unilateral locked facet; case report and literature review. Bull Emerg Trauma 6:367-371. https://doi.org/10.29252/beat-060416

29. Russo S, Belli A, Eynon A, Nader-Sepahi A (2017) Post-traumatic spinal hygroma causing cord compression in type III odontoid fracture with vertical atlantoaxial instability. Spine (Phila Pa 1976) 42: E1092-E1094. https://doi.org/10.1097/BRS.0000000000002081
30. Nowell M, Nelson R (2019) Traumatic posterior atlantoaxial dislocation with associated $\mathrm{C} 1$ Jefferson fracture and bilateral vertebral artery occlusion without odontoid process fracture or neurological deficit. Eur Spine J 28:9-12. https://doi.org/10.1007/s00586-0185678-x

31. Larsen AMG, Grannan BL, Koffie RM, Coumans J-V (2018) Atlantoaxial fusion using $\mathrm{C} 1$ sublaminar cables and $\mathrm{C} 2$ translaminar screws. Oper Neurosurg (Hagerstown) 14:647-653. https://doi.org/10.1093/ons/opx164

32. Hale AT, Dewan MC, Patel B, Geck MJ, Tomycz LD (2017) Instrumented fusion in a 12-month-old with atlanto-occipital dislocation: case report and literature review of infant occipitocervical fusion. Childs Nerv Syst 33:1253-1260. https://doi.org/10.1007/ s00381-017-3497-8

33. Eghbal K, Derakhshan N, Haghighat A (2017) Ocular manifestation of a cervical spine injury: an adult case of traumatic atlantoaxial rotatory subluxation manifesting with nystagmus. World Neurosurg 101:817.e1-817.e3. https://doi.org/10.1016/j.wneu. 2017.02.064

34. Ivetić D, Pavličević G, Antić B (2019) C1-C2 screw fixation in the patient with anomalous course of vertebral artery - a case report. Vojnosanit Pregl 76:555-558. https://doi.org/10.2298/ VSP160622143I

35. Peyriere H, Graillon T, Pesenti S, Tropiano P, Blondel B, Fuentes S (2017) Surgical management of post-traumatic atlantoaxial rotatory fixation due to $\mathrm{C} 2$ facet fracture: 5 clinical cases. Orthop Traumatol Surg Res 103:67-70. https://doi.org/10.1016/j.otsr.2016.09.023

36. He D w, Huang W j, Sheng X y, Wu L j, Fan S w (2016) Atlantoaxial joint interlocking following type II odontoid fracture associated with posterolateral atlantoaxial dislocation: a case report and review of published reports. Orthop Surg 8:405-410. https:// doi.org/10.1111/os. 12255

37. Han K, Cui S-B, Wang L, Wei F-X, Liu S-Y (2016) Traumatic bilateral atlantoaxial rotatory subluxation with hangman fracture in an adult. Neurol India 64:811. https://doi.org/10.4103/00283886.185412

38. Ueda S, Sasaki N, Fukuda M, Hoshimaru M (2016) Surgical treatment for occipital condyle fracture, $\mathrm{C} 1$ dislocation, and cerebellar contusion with hemorrhage after blunt head trauma. Case Rep Orthop 2016:8634831. https://doi.org/10.1155/2016/8634831

39. Dahdaleh NS, Khanna R, Menezes AH, Smith ZA, Viljoen SV, Koski TR, Hitchon PW, Dlouhy BJ (2016) The application of the revised condyle-C1 interval method to diagnose traumatic atlantooccipital dissociation in adults. Glob Spine J 6:529-534. https://doi. org/10.1055/s-0035-1569058

40. Walbom J, Kruse A (2016) Traumatic atlantoaxial rotatory dislocation and displaced ossiculum terminale epiphysiolysis treated with a halo device: a case report. Childs Nerv Syst 32:1321-1325. https:// doi.org/10.1007/s00381-016-3025-2

41. Beez T, Brown J (2017) Traumatic atlanto-occipital dislocation in children - a case-based update on clinical characteristics, management and outcome. Childs Nerv Syst 33:27-33. https://doi.org/10. 1007/s00381-016-3265-1

42. Mendenhall SK, Sivaganesan A, Mistry A, Sivasubramaniam P, McGirt MJ, Devin CJ (2015) Traumatic atlantooccipital dislocation: comprehensive assessment of mortality, neurologic improvement, and patient-reported outcomes at a Level 1 trauma center over 15 years. Spine J 15:2385-2395. https://doi.org/10.1016/j.spinee. 2015.07.003

43. Krishnan P, Kartikueyan R (2015) Traumatic atlantoaxial rotatory subluxation with remote cervical spinal cord contusion in a child. Neurol India 63:279. https://doi.org/10.4103/0028-3886.156313

44. Salunke P, Sahoo SK, Savardekar A, Ghuman M, Khandelwal NK (2015) Factors influencing feasibility of direct posterior reduction in irreducible traumatic atlantoaxial dislocation secondary to 
isolated odontoid fracture. Br J Neurosurg 29:513-519. https://doi. org/10.3109/02688697.2015.1019421

45. Hawi N, Alfke D, Liodakis E, Omar M, Krettek C, Müller CW, Meller R (2016) Case report of a traumatic atlantoaxial rotatory subluxation with bilateral locked cervical facets: management, treatment, and outcome. Case Rep Orthop 2016. https://doi.org/ $10.1155 / 2016 / 7308653$

46. Yang JS, Hao DJ (2015) Traumatic atlantoaxial rotatory subluxation with bilateral locked cervical facets. Spine J 15:1678-1679. https://doi.org/10.1016/j.spinee.2014.07.022

47. Xu Y, Li F, Guan H, Xiong W (2015) Traumatic posterior atlantoaxial dislocation without associated fracture but with neurological deficit: a case report and literature review. Medicine 94: e1768. https://doi.org/10.1097/MD.0000000000001768

48. Hu D, Yang X, Wang J (2015) Traumatic posterior atlantoaxial dislocation without fracture of odontoid process: a case report and systematic analysis of 19 cases. J Orthop Trauma 29:e342-e345. https://doi.org/10.1097/BOT.0000000000000334

49. Salunke P, Sahoo S, Khandelwal NK, Ghuman MS (2015) Technique for direct posterior reduction in irreducible atlantoaxial dislocation: multi-planar realignment of C1-2. Clin Neurol Neurosurg 131:47-53. https://doi.org/10.1016/j.clineuro.2015.01. 025

50. Chaudhary SB, Martinez M, Shah NP, Vives MJ (2015) Traumatic atlantoaxial dislocation with Hangman fracture. Spine J 15:e15e18. https://doi.org/10.1016/j.spinee.2014.12.150

51. Winegar CD, Lawrence JP, Friel BC, Fernandez C, Hong J, Maltenfort M, Anderson PLA, Vaccaro AR (2010) A systematic review of occipital cervical fusion: techniques and outcomes: A review. J Neurosurg Spine 13:5-16. https://doi.org/10.3171/2010. 3.SPINE08143

52. Tanaka N, Atesok K, Nakanishi K, Kamei N, Nakamae T, Kotaka S, Adachi N (2018) Pathology and treatment of traumatic cervical spine syndrome: whiplash injury. Adv Orthop 2018. https://doi.org/ $10.1155 / 2018 / 4765050$

53. Debernardi A, D'Aliberti G, Talamonti G, Villa F, Piparo M, Ligarotti G, Cenzato M (2014) Traumatic injuries to the craniovertebral junction: a review of rare events. Neurosurg Rev 37:203-216. https://doi.org/10.1007/s10143-013-0492-8

54. Goel A, Dhar A, Shah A, Jadhav D, Bakale N, Vaja T, Jadhav N (2019) Central or axial atlantoaxial dislocation as a cause of cervical myelopathy: a report of outcome of 5 cases treated by atlantoaxial stabilization. World Neurosurg 121:e908-e916. https://doi.org/10. 1016/j.wneu.2018.10.009

55. Goel A (2010) Occipitocervical fixation: is it necessary? J Neurosurg Spine 13:1-2. https://doi.org/10.3171/2009.10. SPINE09761
56. Gire JD, Roberto RF, Bobinski M, Klineberg EO, Durbin-Johnson B (2013) The utility and accuracy of computed tomography in the diagnosis of occipitocervical dissociation. Spine J 13:510-519. https://doi.org/10.1016/j.spinee.2013.01.023

57. Goel A, Laheri V (1994) Plate and screw fixation for atlanto-axial subluxation. Acta Neurochir 129:47-53. https://doi.org/10.1007/ BF01400872

58. Harms J, Melcher RP (2001) Posterior C1-C2 fusion with polyaxial screw and rod fixation. Spine:2467-2471. https://doi.org/10.1097/ 00007632-200111150-00014

59. Greenberg M (2019) Handbook of heurosurgery, 9th edn. Thieme, New York ISBN: 9781684201372

60. Kim JY, Oh CH, Yoon SH, Park HC, Seo HS (2014) Comparison of outcomes after atlantoaxial fusion with transarticular screws and screw-rod constructs. J Korean Neurosurg Soc 55:255-260. https:// doi.org/10.3340/jkns.2014.55.5.255

61. Suchomel P, Choutka O (2011) Reconstruction of upper cervical spine and craniovertebral junction. Springer, Berlin Heidelberg. https://doi.org/10.1007/978-3-642-13158-5

62. Wright NM (2004) Posterior C2 fixation using bilateral, crossing C2 laminar screws: case series and technical note. J Spinal Disord 17:158-162. https://doi.org/10.1097/00024720-200404000-00014

63. Meyer D, Meyer F, Kretschmer T, Börm W (2012) Translaminar screws of the axis-an alternative technique for rigid screw fixation in upper cervical spine instability. Neurosurg Rev 35:255-261. https://doi.org/10.1007/s10143-011-0358-x

64. Claybrooks R, Kayanja M, Milks R, Benzel E (2007) Atlantoaxial fusion: a biomechanical analysis of two $\mathrm{C} 1-\mathrm{C} 2$ fusion techniques. Spine J 7:682-688. https://doi.org/10.1016/j.spinee.2006.08.010

65. Ma W, Feng L, Xu R, Liu X, Lee AH, Sun S, Zhao L, Hu Y, Liu G (2010) Clinical application of C2 laminar screw technique. Eur Spine J 19:1312-1317. https://doi.org/10.1007/s00586-010-1447-1

66. Cornelius JF, Kania R, Bostelmann R, Herman P, George B (2011) Transnasal endoscopic odontoidectomy after occipito-cervical fusion during the same operative setting-technical note. Neurosurg Rev 34:115-121. https://doi.org/10.1007/s10143-010-0295-0

67. Messina A, Bruno MC, Decq P, Coste A, Cavallo LM, De Divittis E, Cappabianca P, Tschabitscher M (2007) Pure endoscopic endonasal odontoidectomy: Anatomical study. Neurosurg Rev 30: 189-194. https://doi.org/10.1007/s10143-007-0084-6

Publisher's note Springer Nature remains neutral with regard to jurisdictional claims in published maps and institutional affiliations. 